\title{
Desmovilización sin reinserción: lecciones desde Nicaragua*
}

\author{
Demobilization without Reintegration: Lessons from Nicaragua
}

\author{
Elvira Cuadra Lira ${ }^{\text {a }}$ \\ Facultad Latinoamericana de Ciencias Sociales, Ecuador \\ cuadraelvira@gmail.com \\ ORCID: https://orcid.org/0000-0002-7452-1621
}

DOI: https://doi.org/10.11144/Javeriana.papo25.drln

Recibido: 07 Noviembre 2019

Aceptado: 23 Abril 2020

Publicado: 23 Diciembre 2020

\section{Resumen:}

En este artículo se presenta una descripción del proceso de desmovilización y desarme en Nicaragua durante la década de 1990 , en el pasado siglo XX; los acuerdos internacionales y nacionales que facilitaron la desmovilización de los excombatientes, su cumplimiento y las políticas públicas que ejecutó el gobierno para su reintegración. También se analizan los sucesivos ciclos de rearme que se produjeron por el incumplimiento de los acuerdos, procurando identificar las lecciones aprendidas y los retos pendientes de un proceso inconcluso de construcción de paz que tres décadas después, en el contexto de una crisis sociopolítica, emerge nuevamente en la agenda pública.

Palabras clave: Nicaragua, contras, construcción de paz, desarme, desmovilización, excombatientes, reintegración.

\begin{abstract}
:
This article describes the demobilization and disarmament process in Nicaragua during the 1990s, and the national and international agreements that enabled the demobilization by the ex-combatants, the compliance and the public policies carried out by the government to accomplish their reintegration. This work also analyzes the successive rearmament cycles resulting from not complying with the agreements, and seeks to identify the learnt lessons and the pending challenges of an unaccomplished process of peace construction that, after three decades in the context of a social-political crisis, appears again in the public agenda.
\end{abstract}

Keywords: Nicaragua, counter-actions, peace construction, disarmament, demobilization, ex-combatant, reintegration.

\section{Nicaragua: una pacificación inconclusa}

En enero de 2020, en Nicaragua se cumplieron 30 años de la finalización del largo conflicto bélico que enfrentó a la sociedad durante al menos una década. En Nicaragua el fin del conflicto interno que azotó al país devino como consecuencia de unas votaciones con masiva participación electoral, cuyos resultados fueron interpretados por toda la sociedad nicaragüense como la voluntad de cambiar el gobierno y acabar con la violencia que desangraba al país (Saldomando, 1996). Los resultados electorales de 1990 se convirtieron en el catalizador de un proceso de pacificación ${ }^{1}$ que ya se estaba gestando en alejadas comunidades rurales del interior del país y en el ámbito internacional.

$\mathrm{Al}$ asumir la presidencia en abril de 1990, Violeta Barrios de Chamorro firmó varios acuerdos con la Resistencia Nicaragüense, conocida como "la contra”, para dar inicio a un intenso proceso de desmovilización y desarme de excombatientes que incluyó a las fuerzas de la Resistencia ${ }^{2}$ y más adelante, a los efectivos del Ejército y del Ministerio del Interior que salieron de ambas instituciones en un proceso de reducción de efectivos (Cajina, 1997).

De acuerdo con los datos disponibles, el número de excombatientes desmovilizados de la Resistencia y las fuerzas armadas ascendió a unas 100 mil personas, y las armas entregadas en el proceso de desarme fueron más de 140 mil (Cuadra y Saldomando, 1994; Cuadra et al., 1998; Martí, 2002). Sin embargo, poco tiempo después los excombatientes de uno y otro bando se alzaron nuevamente en armas a causa de la desconfianza,

Notas de autor

$$
\text { a Autora de correspondencia. Correo electrónico: cuadraelvira@gmail.com }
$$


la inseguridad en las zonas rurales y la falta de cumplimiento de los acuerdos firmados con el gobierno. El ciclo de rearme se extendió durante casi toda la década de los 90 y en su punto más alto llegó a alcanzar un estimado de 20 mil hombres (Cuadra y Saldomando, 2000). El rearme se fue extinguiendo gradualmente hasta agotarse totalmente a finales de los 90. De manera que el proceso de reinserción o reintegración de los excombatientes no contó con apoyos significativos del gobierno, sino que transcurrió con recursos propios de los desmovilizados. El abrupto cierre del proceso de desarme, desmovilización y reinserción, además del olvido al que fueron sometidos los excombatientes, resultó en una pacificación inconclusa, con muchos pendientes que se agravaron en el tiempo y acentuaron la decepción de quienes, en esa época, se sintieron héroes de la democracia y la libertad.

Este artículo analiza con una mirada retrospectiva el proceso de reinserción de los excombatientes en Nicaragua durante la década de los 90, tratando de identificar las lecciones que podrían ser útiles para procesos similares en otros países. Aunque el caso de Nicaragua fue el primero en Centroamérica, los detalles de la desmovilización, desarme y reinserción de excombatientes se conocen poco. La base de este análisis es la investigación realizada en esa época por la autora, así como una serie de entrevistas realizadas con excombatientes de la Resistencia y del Ejército, exiliados en Costa Rica a raíz de la crisis política que inició en Nicaragua en 2018. Para ellos, la represión que vivieron recientemente volvió a poner sobre la mesa los aspectos inconclusos de la pacificación, sobre todo porque a pesar de la violencia gubernamental, las acciones de protesta y movilización han sido eminentemente pacíficas.

\section{¿El fin de la guerra?}

A diferencia de otros procesos de pacificación en Centroamérica y otras partes del mundo, en Nicaragua la finalización del conflicto interno no llegó de la mano de acuerdos establecidos entre las partes contendientes (Fisas, 2010), sino como resultado de un proceso electoral donde los nicaragüenses acudieron masivamente a depositar sus votos en las urnas para elegir un nuevo gobierno, pero sobre todo, para poner fin a las muertes, el dolor, la destrucción, la violencia e inseguridad que asolaba al país desde hacía una década

Las elecciones de 1990 fueron el punto culminante de un proceso que incluyó intensas negociaciones internacionales como: Esquipulas I, en 1986; Esquipulas II, en 1987; y Esquipulas III, en 1988. El acuerdo de mayor influencia en la solución de los conflictos bélicos que asolaban a Nicaragua y otros países centroamericanos fue Esquipulas II, "Procedimiento para establecer una paz firme y duradera en Centroamérica”, firmado entre los mandatarios de los países centroamericanos. Entre sus puntos más relevantes están la reconciliación nacional; la democratización y realización de elecciones libres; el cese de ayuda a fuerzas irregulares o movimientos insurreccionales, así como el no uso del territorio para agredir a otros estados; negociaciones en materia de seguridad, verificación, control y limitación de armamento; y un calendario de cumplimiento de los acuerdos y mecanismos para la verificación y el seguimiento internacional.

Mientras tanto, dentro del país el gobierno de Nicaragua también intentaba crear condiciones a su favor para restañar las secuelas de la guerra. Para eso abrió algunas negociaciones con organizaciones políticas de oposición y las fuerzas de la Resistencia Nicaragüense. Uno de los acuerdos internos más importantes previo al cambio de gobierno de 1990, se firmó en 1988, en el poblado de Sapoá, cerca de la frontera sur en Nicaragua. Sus protagonistas fueron el gobierno sandinista de la época, encabezado por el jefe del ejército, General Humberto Ortega, y el directorio de la Resistencia Nicaragüense. Este acuerdo marcó un hito porque era la primera vez que las partes contendientes se sentaban a dialogar, acordaban un cese al fuego y continuar las conversaciones para la desmovilización de las fuerzas irregulares, o la "contra", como les llamaban los simpatizantes del gobierno. Los acuerdos de Sapoá se firmaron el 23 de marzo del 1988 con el cardenal Miguel Obando, arzobispo de Managua, y el secretario general de la Organización de Estados Americanos (OEA), Miguel Baena Soares, como testigos. 
Los aspectos torales fueron el cese al fuego entre las partes contendientes por un período de 60 días; ubicación de las fuerzas de la Resistencia en zonas acordadas mutuamente; amnistía de aplicación gradual para procesados y condenados por violaciones a la Ley del Mantenimiento del Orden y la Seguridad Pública; gestionar y aceptar exclusivamente ayuda humanitaria para la alimentación de las fuerzas irregulares, canalizada a través de organizaciones neutrales; y libertad de expresión garantizada por el gobierno. Una vez que las fuerzas de la Resistencia se concentraran en las zonas acordadas, su directorio enviaría representantes a un espacio denominado "diálogo nacional" para abordar temas de prioridad como el servicio militar. Además, se acordó el retorno e incorporación de las personas que se encontraban en el exterior por razones políticas para que se integraran a los procesos políticos y participaran libremente en las elecciones programadas para febrero de 1990. La supervisión del cumplimiento estaría a cargo de la OEA, Joao Baena Soares y el cardenal Miguel Obando y Bravo. Las fuerzas de la Resistencia Nicaragüense no se desmovilizaron de inmediato, y después de la firma de los acuerdos se fraccionaron en varios grupos (Martí, 2002).

Una vez que conocieron los resultados de las elecciones en 1990, se firmó un acuerdo conocido como "Protocolo de Transición" 3 , que estableció un marco de entendimientos entre el gobierno saliente y el entrante para realizar el traspaso de gobierno y garantizar condiciones básicas de seguridad para toda la sociedad nicaragüense. Entre sus aspectos más importantes estaban la desmovilización de la Resistencia Nicaragüense antes del 25 de abril del 90, día señalado para la toma de posesión del nuevo gobierno; la subordinación de las fuerzas de defensa y de orden público a la autoridad civil, además de un conjunto de cambios para redimensionar las fuerzas armadas y asegurar su obediencia a la autoridad civil ${ }^{4}$; fortalecer la integridad e independencia de los poderes del Estado; proporcionar tranquilidad y seguridad jurídica a las familias beneficiadas con propiedades urbanas y rurales antes del 25 de febrero de 1990; el traspaso ordenado del poder ejecutivo en un marco de mutua seguridad y confianza; garantía de estabilidad en su trabajo a funcionarios y empleados del gobierno; y aunar esfuerzos para gestionar recursos internacionales que permitieran la estabilidad y el crecimiento de la economía nacional (Cuadra, 2009).

Una vez instalado el nuevo gobierno, lo que siguió después ha sido calificado como el fin de la guerra y la pacificación del país, pero en realidad fue un proceso de desmovilización y desarme de excombatientes que acumuló una deuda en materia de reintegración y construcción de paz.

\section{Los acuerdos y su cumplimiento}

Casi inmediatamente después que la señora Violeta Barrios de Chamorro ganara las elecciones en febrero de 1990, se iniciaron las conversaciones con los grupos de la Resistencia Nicaragüense para su desmovilización. Los temas críticos se referían a la desmovilización y reintegración de excombatientes, así como el retorno de miles de nicaragüenses que se encontraban en campamentos y centros de refugio en los países vecinos. Las negociaciones se realizaron por separado con tres grupos distintos: el Frente Democrático Nicaragüense (FDN), el grupo más numeroso con Israel Galeano a la cabeza; el llamado Frente Sur, liderado por Edén Pastora; y Yatama, una coalición de grupos de origen miskito alzados en armas en la Costa Caribe del país. Los acuerdos fueron tres: los de Toncontín, Honduras, en marzo (Agencia EFE, 1990); los de abril en Managua y el 30 de mayo, también en Managua (Cuadra y Saldomando, 1994; Martí, 2002). Cada acuerdo incluyó aspectos distintos (tabla 1 ). 
TABLA 1

Principales acuerdos para la desmovilización de excombatientes

\begin{tabular}{|c|c|c|}
\hline Toncontín & Abril, 1990 & Acuerdos posteriores \\
\hline $\begin{array}{l}\text { Cese al fuego y } \\
\text { desmovilización de fuerzas } \\
\text { antes del } 20 \text { de abril, } 1990 . \\
\text { - Concentración de fuerzas } \\
\text { dentro del territorio en } \\
\text { zonas de seguridad } \\
\text { delimitadas y vigiladas por } \\
\text { organismos internacionales. } \\
\text { Programas de ayuda } \\
\text { gubernamental para } \\
\text { rehabilitación y reinserción } \\
\text { en sociedad. }\end{array}$ & 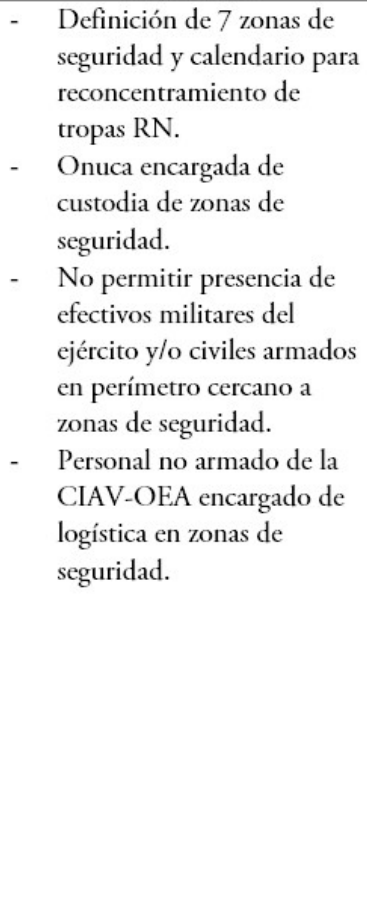 & $\begin{array}{l}\text { - Finalizar la desmovilización } \\
\text { de la Resistencia el } 10 \text { de } \\
\text { junio, } 1990 . \\
\text { - Recoger y destruir armas en } \\
\text { manos de civiles. } \\
\text { - Anunciar planes de } \\
\text { reducción del ejército el } 10 \\
\text { de junio, } 1990 . \\
\text { - Otorgar personería jurídica } \\
\text { a la Resistencia } \\
\text { Nicaragüense para } \\
\text { constituirse en una } \\
\text { organización política. } \\
\text { Determinar zonas para } \\
\text { crear polos de desarrollo de } \\
\text { la Resistencia. } \\
\text { Conformar una policía } \\
\text { rural con efectivos de la } \\
\text { Resistencia. } \\
\text { Tener representación de } \\
\text { RN en ciertos ministerios y } \\
\text { el gobierno local. } \\
\text { Proveer asistencia } \\
\text { económica a los } \\
\text { desmovilizados. }\end{array}$ \\
\hline
\end{tabular}

Fuente: elaboración propia basada en Comisión Negociadora de la Resistencia Nicaragüense y Representantes de la Presidencia de Nicaragua (1990), Gobierno de la República de Nicaragua y Resistencia Nicaragüense (1990a, 1990b, $1990 \mathrm{c})$

Los acuerdos se firmaron en un contexto donde convergieron tres procesos complejos: la transición del proyecto político de la revolución a una democracia liberal; el cambio del modelo económico de la revolución a uno de "libre mercado"; y la pacificación misma (Montenegro et al., 2005). Ni el gobierno ni la Resistencia tenían una estrategia clara para la desmovilización y reintegración de los excombatientes; debido al estado de deterioro de la economía por causa de la guerra, el país no contaba con recursos financieros suficientes para sostener la reintegración de los excombatientes; además, entre los "contras" había un fuerte sentimiento de desconfianza respecto a su seguridad y la de sus familias una vez que se desmovilizaran y entregaran sus armas.

Se estima que el promedio de hombres de la Resistencia desmovilizados entre el 18 y el 30 de mayo de 1990 era de 100 por día; pero luego el proceso se aceleró hasta un promedio de 200, de tal manera que al 10 de junio de ese año se calculaba un total de 7500 desmovilizados, y para finales de ese mismo mes, el total de desmovilizados oficialmente era de 18.994. Los datos de la CIAV-OEA para 1991, citados por Martí (2002), registran un total de 22.413 desmovilizados de la Resistencia; una cantidad muy por encima de lo previsto por los organismos de verificación (Equipo Envío, 1990).

En mayo de ese mismo año, el Ejército de Nicaragua presentó al gobierno un plan para desmovilizar miles de efectivos en tres fases (tabla 2): la primera, en noviembre de 1990; la segunda, en agosto de 1991; y la tercera, en septiembre de 1992 (Cajina, 1997). En 1993, el general Humberto Ortega, jefe del Ejército, presentó un informe a la Organización de Estados Americanos (OEA), donde consignaba que la institución militar se había reducido de 90 mil hombres en 1990, a 15.200 efectivos en junio de 1993 (Equipo Envío, 1993). Otros 5000 efectivos desmovilizados provenientes de diferentes dependencias del Ministerio del Interior se agregaron a esas listas, de tal manera que el estimado total de desmovilizados alcanza un poco menos de 99.000 hombres. 
TABLA 2

Hombres oficialmente desmovilizados, 1990-1993

\begin{tabular}{lr}
\hline Resistencia Nicaragüense & 18.994 \\
\hline Ejército Popular Sandinista & 74.800 \\
\hline Ministerio del Interior & 5100 \\
\hline Total & 98.894 \\
\hline
\end{tabular}

Fuente: elaboración propia

\section{La reintegración económica: los polos de desarrollo}

Uno de los aspectos clave de los acuerdos firmados entre el gobierno Chamorro y la Resistencia fue la creación de polos de desarrollo para el establecimiento y reinserción de los excombatientes desmovilizados. Estos estaban concebidos como enclaves de seguridad que contarían con condiciones y servicios básicos para facilitar el proceso de reinserción de los desmovilizados, a través de proyectos individuales o colectivos. Entre los servicios que se instalarían, estaban escuelas, bodegas, agua potable, luz eléctrica, hospitales, calles, caminos, áreas de vivienda, parcelas de propiedad privada para cultivos y ganadería de subsistencia, área comunal y área de proyectos. Las zonas definidas fueron Río Blanco y El Almendro, en la zona central del país; Yolaina, Silmalila y Wisconsin, en la región norte de la Costa Caribe, y Nueva Guinea en la zona sur central. Un total aproximado de $8000 \mathrm{~km} 2$.

Aunque los desmovilizados se asentaron en los sitios definidos para instalar los polos de desarrollo, muy pronto se dieron cuenta de que los acuerdos no pasarían de ser una declaración de buenas intenciones, pues nunca contaron los recursos necesarios para su implementación; de manera que pocos meses después de la desmovilización, los excombatientes de la Resistencia comenzaron a abandonarlos para regresar a sus comunidades de origen o a las zonas donde realizaban sus operaciones militares para reintegrarse económica y socialmente por sus propios medios (Martí i Puig, 1998). En el caso del Ejército, los desmovilizados recibirían el pago de una indemnización y tierras para su reinserción a la vida económica del país.

En el Ministerio de Gobernación se instaló una oficina para dar seguimiento al cumplimiento de los acuerdos, especialmente la entrega y titulación de tierras. Nunca se conoció el resultado de su gestión; de hecho, el único documento elaborado por el gobierno de Nicaragua sobre el proceso de pacificación no circuló públicamente[5] (Gobnic-PNUD, 1995). En ese documento se consigna cuántos desmovilizados fueron beneficiados con la entrega de tierras y la cantidad entregada (tabla 3 ).

TABLA 3

Cantidad de desmovilizados que recibieron tierras y área entregada, 1990-1994

\begin{tabular}{lrr}
\hline Grupo & Beneficiados & Área (ha) \\
\hline Resistencia Nicaragüense & 13.553 & $337.114,4$ \\
\hline Ejército Popular Sandinista & 3149 & 58.660 \\
\hline Ministerio del Interior & 389 & 9082,5 \\
\hline Total & 17.091 & $404.856,9$ \\
\hline
\end{tabular}


Aunque la mayoría de los integrantes de la Resistencia y del Ejército eran de origen campesino, la cantidad de desmovilizados que recibieron tierras fue pequeña, además, la entrega fue desigual, pues algunos recibieron propiedades extensas de gran valor productivo, mientras otros recibieron pequeñas parcelas y pobre vocación productiva. La entrega de tierras tampoco se acompañó con programas de asistencia técnica ni créditos productivos por parte del gobierno; además, el proceso de titulación se prolongó en el tiempo, impidiéndoles acceder a préstamos en las instituciones bancarias. La tierra fue, y es todavía, el bien más preciado para los excombatientes; de manera que la falta de políticas complementarias relacionadas con créditos, asistencia técnica y capacitación, así como la aplicación de políticas de ajuste y reforma económica durante toda la década de los 90, impactaron fuertemente a los beneficiados provocando inseguridad jurídica, pérdida del bien por venta en el mercado negro o por ejecuciones bancarias, y descapitalización. Eso alimentó uno de los conflictos más profundos de las últimas 4 décadas en Nicaragua: los conflictos por la propiedad; pero, además, provocó un proceso de precarización de miles de desmovilizados y sus familias que perdura hasta hoy (Cuadra y Saldomando, 2000).

\section{La reintegración social: una realidad compartida}

Mientras tanto, la reinserción social avanzó con una dinámica diferente. Un aspecto clave en el posconflicto se refiere al esclarecimiento de la verdad; generalmente, los países que han transitado por ese tipo de procesos establecen comisiones de la verdad para sentar las bases de la reconciliación y la reinserción social (Fisas, 2001). Pero en el caso de Nicaragua, los actores políticos no consideraron necesario instalar una comisión de la verdad u otro mecanismo que permitiera establecer la verdad de lo sucedido, de manera que ese punto no fue incluido en ninguno de los acuerdos para la desmovilización. (Equipo Envío, 1993). Ese ha sido uno de los vacíos más grandes en la historia reciente del país y hasta ahora no se conoce ni se ha documentado lo sucedido durante el largo conflicto que vivió el país.

La reconciliación entre los excombatientes inició casi inmediatamente después de la desmovilización, y a pesar de la desconfianza, los prejuicios, la polarización y el deseo de venganza entre los dos grupos. Poco tiempo después, distintas organizaciones sociales, especialmente aquellas que se encontraban en las zonas donde se asentaron los desmovilizados, iniciaron procesos más dirigidos para la construcción de una cultura de paz y la reconciliación entre los excombatientes (Centro de Estudios Internacionales, 1995, 2010).

De esos procesos surgieron redes de promotores de paz que durante muchos años contribuyeron a la mediación de conflictos comunitarios, especialmente durante el proceso de rearme de excombatientes que se produjo casi inmediatamente después de la desmovilización (Cuadra et al., 1998). Tres experiencias destacan en ese período: las comisiones de paz promovidas por la iglesia evangélica (Mouly, 2013); la red de promotores creada por el Centro de Estudios Internacionales (CEI); y la red de mediadores promovida por la Comisión Internacional de Apoyo y Verificación (CIAV) de la OEA

Los discursos oficiales alentaban a los desmovilizados, especialmente a los originarios de las zonas rurales, a recuperar su identidad "campesina". Eso, junto a la falta de cumplimiento de los acuerdos, terminó de convencer a los desmovilizados de uno y otro bando que su situación era similar y que la demanda de "tierra, techo y trabajo" era igual. Las fronteras ideológicas y las desconfianzas fueron desapareciendo entre ellos para unirlos en sus reclamos al gobierno (Cuadra y Saldomando, 2000).

\section{La reintegración politica: entre la participación y la reivindicación}

Desde el inicio de las negociaciones, la Resistencia Nicaragüense tenía expectativas de convertirse en partido político para participar como actores legítimos en los procesos electorales y otros espacios del sistema político. El Partido de la Resistencia Nicaraguense se constituyó formalmente hasta 1993, tres 
años después de la desmovilización. Inicialmente contó con 40 mil afiliados; sin embargo, con el tiempo sufrió fraccionamientos y escisiones que lo debilitaron hasta prácticamente desaparecer, por lo que terminó aliandose con otros partidos políticos. A través de esas alianzas varios de sus directivos fueron elegidos para cargos de diputación; sin embargo, terminaron distanciándose del resto de la membresía que finalmente se integró mayoritariamente a otros partidos.

Los desmovilizados también crearon numerosas organizaciones para reivindicar el cumplimiento de los acuerdos firmados con el gobierno, muchas todavía existen y han mantenido un reclamo público constante frente a los diferentes gobiernos que se han sucedido desde 1990 hasta la fecha en relación con el cumplimiento de los acuerdos y el reconocimiento de su estatus como excombatientes y veteranos de un conflicto. En el 2013, después de 13 años de presiones, la Asamblea Nacional aprobó la Ley Especial para atención a Excombatientes por la paz, unidad y reconciliación nacional (La Gaceta, 2013). Previamente, en el 2007, el gobierno de Daniel Ortega creó una Comisión de Reconciliación y Paz presidida por el cardenal Miguel Obando y Bravo, una reconocida figura religiosa que medió para la finalización del conflicto a finales de los 80 ("Daniel instala Comisión”, 2007). Ninguno de los dos instrumentos resultó efectivo para avanzar en el cumplimiento de los acuerdos.

\section{Políticas públicas y cooperación}

En las sociedades posconflicto, uno de los factores más importantes para la construcción de la paz y la reinserción de los excombatientes es la acción del Estado y el apoyo de la cooperación internacional, pues se trata de entornos frágiles que requieren acciones específicas para fortalecer los tejidos sociales y facilitar condiciones para la reintegración. Sin embargo, las complejidades de la pacificación en Nicaragua condicionaron tanto al Estado como a la cooperación internacional.

\section{La limitada acción estatal}

El proceso de desmovilización, desarme y reintegración de los excombatientes transcurrió en Nicaragua sin que de parte del gobierno y de los propios desmovilizados existiera una estrategia para orientar las acciones. La premisa que guió las decisiones gubernamentales en materia económica fue la de facilitar el proceso de reinserción a la globalización y lograr la estabilidad económica después de un largo período de guerra. Mantener esa premisa significó castigar políticas sociales, una de ellas, la reintegración de los excombatientes. Para la época en que finalizó el conflicto armado, el total de la población estimada en Nicaragua era de unos 4 millones de personas; un poco más de 500 mil habían sido afectadas directamente por la guerra (tabla 4), ya fuera porque participaron como combatientes, o porque eran refugiados o desplazados. Aproximadamente la mitad de esta población se ubicó en 69 de los 153 municipios existentes en el país. 
TABLA 4

Víctimas directas del conflicto

\begin{tabular}{lr}
\hline Refugiados en Honduras y Costa Rica & 71.000 \\
\hline Desmovilizados Resistencia Nicaragüense & 18.994 \\
\hline Familiares Resistencia Nicaragüense & 58.721 \\
\hline Desmovilizados Ejército Popular Sandinista & 74.800 \\
\hline Desmovilizados Ministerio del Interior & 5100 \\
\hline Desplazados internos & 354.000 \\
\hline Total & 582.615 \\
\hline
\end{tabular}

Fuente: Cuadra y Saldomando (1994), Cuadra et al. (1998) y Martí (2002)

Esas cifras muestran las dimensiones del reto al que se enfrentaba el gobierno y la sociedad nicaragüense; sin contar que el resto de la población había sido afectada indirectamente por la guerra.

Uno de los acuerdos para la desmovilización consistió en la creación de un Ministerio de Repatriciación que se encargaría del retorno, repatriación y reintegración de los integrantes de la Resistencia, sus familiares y otros refugiados que se encontraban en campamentos instalados en Honduras y Costa Rica. El Ministerio en realidad nunca funcionó a plena capacidad ni contó con los recursos suficientes para cumplir con la misión encomendada, mientras que otras acciones del gobierno se ejecutaron de manera aislada y temporal, con un énfasis de asistencia humanitaria más que de reintegración. Las necesarias coordinaciones interinstitucionales y la designación de fondos para el cumplimiento de acuerdos específicos como los polos de desarrollo, nunca se efectuaron (Gobnic-PNUD, 1995).

Inicialmente, el gobierno había definido 7 ejes de acción prioritarios, de los cuales 5 se relacionaban con el proceso de pacificación, a saber: desmovilización de grupos armados por métodos no violentos y su reinserción en la sociedad; beneficios a los desmovilizados; creación de la Brigada Especial de Desarme (BED); programas socioeconómicos en las regiones y poblaciones afectadas por el conflicto; y profesionalización de las fuerzas armadas (Gobnic-PNUD, 1995). Pero las expectativas y previsiones del gobierno y de los propios desmovilizados no se cumplieron, pues chocaron contra la devastadora realidad de una sociedad agotada por la guerra, infraestructura destruida, fondos de cooperación condicionados y escasos (Rueda Estrada, 2019).

\section{Las misiones internacionales}

Las dos misiones más importantes para la desmovilización, desarme y reintegración de excombatientes en Nicaragua fueron la Misión de Naciones Unidas para Centroamérica (Onuca) y la Comisión Internacional de Apoyo y Verificación de la OEA (CIAV-OEA). La Onuca inició sus operaciones en noviembre de 1989 y las culminó en enero de 1992. Estaba compuesta por 260 observadores militares, un batallón de infantería de aproximadamente 800 efectivos entre oficiales y tropa, tripulación y personal de apoyo para una brigada aérea y una unidad naval; así como personal civil de contratación internacional y local que llegó a Nicaragua por mandato del Consejo de Seguridad de la ONU. Entre sus tareas estaban verificar el cumplimiento de los compromisos adquiridos en materia de seguridad por los cinco gobiernos centroamericanos firmantes de los acuerdos de Esquípulas II; supervisar el cese al fuego entre las fuerzas beligerantes, la desmovilización de la Resistencia Nicaragüense y la destrucción del armamento entregado. Una vez que consideraron cumplido su mandato, se retiraron del país.

La CIAV-OEA inició sus actividades en 1990 y extendió su mandato prácticamente hasta finales de esa década. Su principal tarea consistió en apoyar la desmovilización de excombatientes y asegurar su retorno 
a las comunidades a través de varios proyectos como el apoyo logístico de las zonas señaladas para la desmovilización de la Resistencia, la conformación de comisiones de paz, apoyo al Instituto de Reforma Agraria para facilitar la reinserción de excombatientes en las áreas rurales, apoyo al desarrollo municipal y la rehabilitación de excombatientes en la zona norte del país, monitorear el respeto a los derechos humanos y participar la Comisión Tripartita junto con el gobierno de Nicaragua y el Cardenal Miguel Obando y Bravo (Comisión Interamericana de Derechos Humanos, 1993).

\section{La cooperación internacional}

En un país destruido por la guerra, con varios años de bloqueo comercial y con tres grandes retos por delante, la cooperación internacional se convirtió en un factor clave para la pacificación y la recuperación posconflicto. En efecto, una vez que se realizó el traspaso de gobierno en 1990, se produjo un retorno de fuentes de cooperación importantes para Nicaragua, entre ellas, los organismos financieros internacionales como el Fondo Monetario Internacional (FMI) y el Banco Mundial; agencias internacionales multilaterales como el Sistema de Naciones Unidas, y agencias de cooperación bilateral, entre ellas la Agencia de los Estados Unidos para el Desarrollo Internacional (Usaid), una de las más importantes. Pero no todas regresaron a Nicaragua con fondos de apoyo para el proceso de paz o la reintegración de los excombatientes; en realidad, los montos destinados para este proceso fueron más bien escasos.

En el lapso de 6 años, se destinaron un poco menos de 500 millones de dólares para la pacificación, aunque el énfasis más importante se encuentra entre 1990 y 1993, cuando se destinaron fondos de cooperación para aspectos sensibles como la desmovilización y reconstrucción (tabla 5). Después de ese año, el énfasis de los fondos de cooperación, aun los destinados a la pacificación, hacían énfasis en proyectos de infraestructura, productivos y otros más relacionados con el desarrollo rural.

TABLA 5

Fondos de cooperación destinados a la pacificación

\begin{tabular}{lr}
\hline Concepto & $\begin{array}{r}\text { US \$ } \\
\text { (millones) }\end{array}$ \\
\hline Misión ONU para Centroamérica & 88,5 \\
\hline Acuerdos de desmovilización & 99 \\
\hline Gobierno de Nicaragua & 23,6 \\
\hline Programas de Cooperación & 195,7 \\
\hline CIAV-OEA & 59,7 \\
\hline Víctimas civiles & 5,4 \\
\hline
\end{tabular}

Fuente: elaboración propia con base en Gobnic-PNUD (1995) y Cuadra et al. (1998)

Los proyectos estaban orientados a 1) la desmovilización, desarme y reubicación de excombatientes, que estaban ejecutados por la Onuca y la CIAV-OEA; y 2) reinserción, rehabilitaión y reconstrucción, apoyados principalmente por la Unión Europea y las agencias de Naciones Unidas, así como algunas agencias de cooperación bilateral. A instancias de la cooperación, el gobierno creó el Programa de Reconstrucción y Reconciliación Nacional (PRRN) en 1991, sin embargo no contó con mayor apoyo ni proyección desapareciendo al poco tiempo. 


\section{Recontras, recompas y revueltos: un nuevo ciclo de violencia armada}

El ciclo de rearme de excombatientes reclamando el cumplimiento de los acuerdos se extendió prácticamente desde el año 1991 hasta finales de la década de los 90. Los primeros grupos decidieron llamarse "recompas" y "recontras" en alusión a los apelativos que ambos grupos utilizaban durante el conflicto ${ }^{6}$. Más adelante se formaron grupos mixtos que fueron conocidos como "revueltos". Se estima que en las diferentes oleadas de rearme llegaron a participar unos 20 mil hombres y se firmaron nuevos acuerdos con el gobierno que tampoco se cumplieron (Cuadra et al., 1998; Cuadra y Saldomando, 2000; Rueda Estrada, 2015).

El año en el que se produjeron más acciones armadas fue en 1993 (tabla 6), y comenzaron a disminuir a partir de 1994 hasta prácticamente extinguirse en 1999. En algunos casos las acciones armadas fueron tan beligerantes que llegaron hasta la ocupación de ciudades importantes como sucedió en Estelí, cuando un grupo de "recompas" jefeados por un desmovilizado del Ejército conocido como "Pedrito, el hondureño" atacó la ciudad y tomó control temporal de la misma por varios días hasta que fue desalojado por tropas militares (Orgambides, 1993)

TABLA 6.

Acciones armadas, 1991-1999

\begin{tabular}{ccccccccc}
\hline 1991 & 1992 & 1993 & 1994 & 1995 & 1996 & 1997 & 1998 & 1999 \\
\hline 291 & 378 & 709 & 407 & 248 & 85 & 38 & 28 & 17 \\
\hline
\end{tabular}

Fuente: Policía Nacional de Nicaragua (1992, 1993, 1994, 1995, 1996, 1997, 1998, 2000)

La lógica de los distintos rearmes consistía en organizar grupos de desmovilizados encabezados por ellos mismos, y realizar acciones armadas para obligar al gobierno a firmar nuevos acuerdos; cada grupo de líderes negociaba un paquete de beneficios para ellos y sus allegados, mientras dejaban fuera a la mayoría del grupo. Eso dio lugar a un dinámico proceso de cooptación por parte del gobierno, y en cada rearme el contenido de los acuerdos se volvía más general.

Para los años 1995-1996, el gobierno decidió cerrar las negociaciones con los rearmados, así como el proceso de paz, catalogando a los grupos como "bandas rurales" y argumentando que ya no se trataba de excombatientes sino de forajidos o delincuentes comunes. En efecto, la composición de los grupos se modifi có con la incorporación de campesinos empobrecidos y algunas personas con antecedentes delictivos. Los años de mayor auge para las bandas fueron 1998 y 1999, operaban en las mismas zonas geográficas de los grupos rearmados, y en 1998 las mismas autoridades reconocieron la existencia de 184 bandas rurales (Policía Nacional de Nicaragua, 1999). Gradualmente las bandas desaparecieron mientras el gobierno realizaba planes de seguridad en el campo con participación conjunta del ejército y la policía.

\section{Lecciones aprendidas: tres décadas después}

Casi 30 años después de iniciar el proceso de paz, Nicaragua inició una ola de movilización y protesta social en abril de 2018 que se ha mantenido en el tiempo. Además de los jóvenes, las mujeres y ciudadanos en general, a ella se sumaron miles de campesinos en todo el país. El gobierno respondió con una política de represión que ha involucrado a las fuerzas de la policía y grupos de civiles fuertemente armados (Comisión Interamericana de Derechos Humanos, 2018; Grupo Interdisciplinario de Expertos Independientes Nicaragua, 2018). Una buena parte de los campesinos que han participado en estas protestas son desmovilizados de la Resistencia Nicaragüense y del Ejército; en las zonas rurales, ellos y otros protestantes organizaron cortes de carretera, o tranques como les llama la gente, para impedir el paso de vehículos. Los tranques fueron removidos por la fuerza con acciones cuasi militares, por la policía y los grupos civiles armados provocando cientos de muertos y obligando a miles de campesinos a huir hacia los países vecinos (Comisión Interamericana de 
Derechos Humanos, 2018). Para los desmovilizados de la Resistencia y del Ejército, esta experiencia reciente trae a la memoria los días de la guerra y la pacificación.

\section{Las lecciones aprendidas}

En sus relatos anteriores y actuales, los desmovilizados identifican lecciones aprendidas del proceso de construcción de paz a inicios de los 90. La primera es que ese proceso dejó una agenda de paz inconclusa, con aspectos sin resolver para la reinserción, especialmente en el ámbito económico, el reconocimiento social y la promoción de una cultura de paz. Identifican al gobierno como uno de los principales responsables de ese olvido, todavía demandan el cumplimiento de los acuerdos firmados hace ya casi tres décadas y demandan un espacio de participación política en la sociedad nicaragüense.

Desde su perspectiva, una de las más importantes lecciones aprendidas es la capacidad de los tejidos sociales comunitarios para acogerlos y reintegrarlos a diferentes ámbitos de la vida aun sin el apoyo del gobierno. En ese sentido, muchos de ellos se convirtieron en líderes sociales, activistas comunitarios, facilitadores judiciales y ciudadanos que aportan a sus localidades. Ese fue un proceso que inició desde antes de 1990 con la experiencia de las comisiones de paz en las zonas rurales y se reforzó en los años subsiguientes con la participación de los desmovilizados en distintas localidades. De acuerdo con Mouly (2013), las comisiones de paz han tenido varios momentos (tabla 7 ).

TABLA 7

Evolución de las comisiones de paz, años 1980-2012

\begin{tabular}{|c|c|c|c|}
\hline Período & $\begin{array}{l}\text { Años } 1980 \\
\text { (Guerra Contra) }\end{array}$ & $\begin{array}{l}1990-1997 \\
\text { (Posguerra, grupos } \\
\text { rearmados) }\end{array}$ & 1997-2012 \\
\hline $\begin{array}{l}\text { Localización } \\
\text { geográfica } \\
\text { principal }\end{array}$ & $\begin{array}{l}\text { Sur de la región central y } \\
\text { noroeste }\end{array}$ & Sur y oeste de la región central & Sur y este de la región central \\
\hline Actividades & $\begin{array}{l}\text { Negociar con las partes } \\
\text { beligerantes para proteger a } \\
\text { la población civil. } \\
\text { - Facilitar las negociaciones } \\
\text { de paz entre el gobierno y } \\
\text { las fuerzas de la Contra. }\end{array}$ & $\begin{array}{l}\text { - } \\
\text { regociar con los grupos } \\
\text { estatales para proteger } \\
\text { civiles. } \\
\text { - } \\
\text { Facilitar las negociaciones } \\
\text { entre el Estado y los grupos } \\
\text { rearmados. } \\
\text { Mediación de disputas } \\
\text { locales. }\end{array}$ & $\begin{array}{l}\text { - Mediar disputas locales. } \\
\text { - Atender violaciones a los } \\
\text { derechos humanos. } \\
\text { - Conducir capacitaciones } \\
\text { para la resolución pacífica } \\
\text { de conflictos y los derechos } \\
\text { humanos. } \\
\text { - Contribuir al desarrollo de } \\
\text { proyectos. }\end{array}$ \\
\hline
\end{tabular}

Fuente: Mouly (2013)

Lo cierto es que estas comisiones y otras estructuras similares se convirtieron en un fuerte tejido de organización y participación ciudadana que se ha sostenido en el tiempo y facilitado la canalización de conflictos a través de mecanismos institucionales. Este es uno de los capitales políticos y sociales más importantes de la sociedad nicaragüense en las últimas décadas, y ha sido la piedra angular del movimiento cívico y las acciones de protesta efectuadas desde abril de 2018 hasta la actualidad.

Otra lección aprendida se refiere al uso de medios cívicos y pacíficos para la protesta pública. Los excombatientes son los primeros en argumentar que los métodos violentos y las acciones armadas no son recursos legítimos ni deseados para el cambio político. La crisis de abril de 2018 ha hecho emerger como nunca los numerosos relatos de los excombatientes sobre las dificultades de la construcción de paz, la reconciliación y su reinserción en las comunidades una vez que se desmovilizaron. Esos relatos permanecieron varias décadas silenciados, pero no fueron olvidados. Ahora emergen nuevamente para fortalecer la vocación cívica y pacífica de los nicaragüenses, especialmente las generaciones jóvenes. ${ }^{7}$ 


\section{La agenda pendiente y nuevos problemas}

La desmovilización y desarme no facilitó la reinserción de los excombatientes. Treinta años después “tierra, techo y trabajo" son las demandas vigentes de un enorme sector de población que se encuentra cada día más pauperizado y ha sido forzado a dejar atrás su pasado. Los conflictos por la tierra vinculados estrechamente con los acuerdos para la pacificación, y que aún permanecen vivos, son la expresión más viva de esa agenda pendiente.

El regreso del Frente Sandinista de Liberación Nacional a la presidencia en 2007 reavivó las esperanzas y expectativas de miles de hombres y mujeres víctimas de la guerra al instalar la Comisión Nacional de Verificación, Reconciliación, Paz y Justicia, encabezada por el cardenal Miguel Obando; sin embargo, sin un presupuesto asignado y con problemas de coordinación, la Comisión no funcionó y el desencanto volvió a las vidas de los desmovilizados.

Mientras tanto, en las localidades rurales donde la Resistencia Nicaragüense todavía tiene grupos importantes, emergió nuevamente la polarización, la desconfianza y la violencia política. Diversos organismos de derechos humanos han denunciado públicamente los asesinatos selectivos de líderes de la Resistencia; una ola de muertes violentas que se ha incrementado desde octubre de 2018 hasta agosto de 2019 (Colectivo de Derechos Humanos Nicaragua Nunca Más et al., 2019).

La crisis de 2018 volvió a poner en discusión los avances de la pacificación en Nicaragua, como un proceso trunco, inconcluso. Una realidad que no ha cambiado mucho con el tiempo. Pero sobre todo ha abierto una oportunidad para restañar de una vez las heridas, rescatar la memoria de esa experiencia, esclarecer el pasado y construir la paz sobre bases firmes.

\section{Referencias}

Agencia EFE. (1990, 25 de marzo). El compromiso de Toncontín. El País. https://elpais.com/diario/1990/03/25/in ternacional/638319607_850215.html

Cajina, R. (1997). Transición política y reconversión militar en Nicaragua. 1990 - 1995. Coordinadora Regional de Investigaciones Económicas y Sociales.

Centro de Estudios Internacionales. (1995). Hablan los desmovilizados de guerra: Nicaragua, El Salvador y Mozambique.

Centro de Estudios Internacionales. (2010). 1991-2000: Nueve años aportando a la construcción de la Paz en Nicaragua.

Comisión Interamericana de Derechos Humanos. (1993). Informe Anual 1992-1993. http://www.cidh.org/annualr ep/92span/cap.4b.htm

Comisión Interamericana de Derechos Humanos. (2018). Graves violaciones a los derechos humanos en el marco de las protestas sociales en Nicaragua.

Comisión Negociadora de la Resistencia Nicaragüense y Representantes de la Presidencia de Nicaragua. (1990). Acuerdo de Toncontín.

Colectivo de Derechos Humanos Nicaragua Nunca Más, Acción Penal, Fundación para el Debido Proceso, y Movimiento Campesino de Nicaragua. (2019). Situación de los derechos humanos de la población campesina.

Cuadra, E. (2009). La transición hacia la democracia en Nicaragua. En C. Barrachina (ed.), Democracias en transición en Honduras y Nicaragua. Gobernabilidad, seguridad y defensa (pp. 141-158). Plaza y Valdés.

Cuadra, E., y Saldomando, A. (1994). Los problemas de la pacificación en Nicaragua. Recomposición de grupos armados y conflictos sociales. Coordinadora Regional de Investigaciones Económicas y Sociales.

Cuadra, E., y Saldomando, A. (2000). Conflictos rurales en Nicaragua: las tierras de la discordia. Centro de Estudios Iinternacionales. 
Cuadra, E., Pérez Baltodano, A., y Saldomando, A. (1998). Orden social y gobernabilidad en Nicaragua. 1990-1996. Coordinadora Regional de Investigaciones Económicas y Sociales.

Daniel instala Comisión de Reconciliación y Paz en Nicaragua. (2007, 10 de mayo). La Voz del Sandinismo. https://www.lavozdelsandinismo.com/nicaragua/2007-05-10/daniel-instala-comision-de-reconci liacion-y-paz-en-nicaragua

Equipo Envío. (1990, julio). Los contras de Franklin: ¿cuál será su futuro? Envio, 105. https://www.envio.org.ni/ar ticulo/635

Equipo Envío. (1993, junio). Nicaragua. Noticias del mes. Envío, 138. https://www.envio.org.ni/articulo/2443

Expediente Público. (2020, 27 de junio). Nicaragua campesina, la nación ajena [video]. YouTube. https://www.yout ube.com/watch?v=12PL6qu6Xhs

Fisas, V. (2001). Cultura de paz y gestión de conflictos. Icaria Editorial.

Fisas, V. (2010). iAlto el fuego! Manual de procesos de paz. Icaria Editorial.

Grupo Interdisciplinario de Expertos Independientes Nicaragua. (2018). Informe sobre los hechos de violencia ocurridos entre el 18 de abril y el 30 de mayo de 2018.

Gobierno de la República de Nicaragua y Resistencia Nicaragüense. (1990a). Acuerdo del Cese del fuego efectivo y definitivo entre el Gobierno de la República de Nicaragua y la Resistencia Nicaragüense.

Gobierno de la República de Nicaragua y Resistencia Nicaragüense. (1990b). Acuerdo para el establecimiento de Polos de Desarrollo entre el Gobierno y la Resistencia Nicaragüense.

Gobierno de la República de Nicaragua y Resistencia Nicaragüense. (1990c). Protocolo de Managua para el Desarme. Gobnic-PNUD. (1995). El proceso de pacificación en Nicaragua. 1990-1994 [texto inédito].

La Gaceta. (2013). Ley No. 830. Ley Especial para Atención a Excombatientes por la Paz, Unidad y Reconciliación Nacional.

Martí i Puig, S. (1998, julio-agosto). La violencia política en Nicaragua. Elites, bases sandinistas y contras en los 90. Nueva Sociedad, 156. https://nuso.org/articulo/la-violencia-politica-en-nicaragua-elites-bases-sandinistas-y-co ntras-en-los-90/

Martí, S. (2002). El proceso de desmovilización y "reinserción" de la contra nicaraguense: algunas claves para el análisis de la violencia rural en Nicaragua. Cidob. https://www.cidob.org/es/articulos/monografías/ el_proceso_de_desmovilizacion_y_reinsercion_de_la_contra_nicaragueense_algunas_claves_para_el_analisis

Montenegro, S., Cuadra, E., Saldomando, A., y Zamora, Y. (2005). Nicaragua: la gobernabilidad al servicio de las reformas. Cinco.

Mouly, C. (2013). The Nicaraguan Peace Commissions: A Sustanaible Bottom-Up Peace Infraestructure. International Peacekeeping 20(1), 48-66. https://www.doi.org/10.1080/13533312.2012.761833

Orgambides, F. (1993, 23 de julio). Managua recupera Estelí tras dos días de luchas que causaron unos treinta muertos y cien heridos. El País. https://elpais.com/diario/1993/07/23/internacional/743378413_850215.html

Policía Nacional de Nicaragua. (1992). Anuario estadístico 1991.

Policía Nacional de Nicaragua. (1993). Anuario estadístico 1992.

Policía Nacional de Nicaragua. (1994). Anuario estadístico 1993.

Policía Nacional de Nicaragua. (1995). Anuario estadístico 1994.

Policía Nacional de Nicaragua. (1996). Anuario estadístico 1995.

Policía Nacional de Nicaragua. (1997). Anuario estadístico 1996.

Policía Nacional de Nicaragua. (1998). Anuario estadístico 1997.

Policía Nacional de Nicaragua. (1999). Anuario estadístico 1998.

Policía Nacional de Nicaragua. (2000). Anuario estadístico 1999.

Rueda Estrada, V. (2015). Recompas, recontras, revueltos y rearmados: posguerra y conflictos por la tierra en Nicaragua. 1990-2008. Instituto de Investigaciones Dr. José María Luis Mora; Universidad Nacional Autónoma de México. 
Rueda Estrada, V. (2019). Movilizaciones campesinas en Nicaragua (1990-2018): De los Rearmados a los Autoconvocados. Cuadernos Intercambio sobre Centroamérica y el Caribe, 16(2). http://doi.org/10.15517/c.a..v16 i2.37499

Saldomando, A. (1996). Nicaragua: con el futuro en juego. Coordinadora Regional de Investigaciones Económicas y Sociales.

\section{Notas}

* Artículo de investigación científica

[1] En la narrativa nicaragüense, se denomina como "pacificación” al proceso de desmovilización, desarme y construcción de paz que se efectuó durante toda la primera mitad de los años 90.

[2] Los tres acuerdos más importantes para la desmovilización y desarme de la Resistencia Nicaragüense fueron a) El Acuerdo de Toncontín, firmado en Honduras, el 23 de marzo de 1990; b) el Acuerdo del cese al fuego efectivo y definitivo entre el Gobierno de la República de Nicaragua y la Resistencia Nicaragüense, firmado en Managua el propio 25 de abril, día de la toma de posesión del nuevo gobierno; y c) el "Protocolo de Managua sobre el desarme" y el "Acuerdo para el establecimiento de Polos de Desarrollo”, firmados en Managua el 30 de mayo de 1990.

[3] Su nombre es: Protocolo para la Transferencia del Mando Presidencial del Gobierno de la República de Nicaragua. Se firmó en marzo de 1990.

[4] Los cambios acordados fueron redimensionar tamaño y características de acuerdo con las condiciones del país y los acuerdos suscritos en Contadora, y entre los presidentes de la región centroamericana; el carácter profesional y no partidista; respeto a la integridad institucional, rangos, escalafones y mandos del Ejército y las fuerzas de orden público.

[5] El documento fue elaborado conjuntamente entre el Gobierno de Nicaragua y el Programa de Naciones Unidas para el Desarrollo (PNUD) en el año 1995. Fue titulado “El proceso de pacificación en Nicaragua. 1990-1994". Una copia del original se encuentra en manos de la autora de este artículo.

[6] Los combatientes de la Resistencia Nicaragüense fueron llamados "contras"; mientras que los combatientes del ejército se llamaban entre ellos "compañeros" o "compas".

[7] El deseo de esclarecer la verdad se ha reavivado en la sociedad nicaragüense y ha dado lugar a trabajos de reconstrucción de la memoria como el documental Nicaragua campesina. La nación ajena, que hace un recuento de las experiencias de los desmovilizados de la Resistencia Nicaragüense y la represión que han vivido desde hace varias décadas (Expediente Público, 2020).

\section{Licencia Creative Commons CC BY 4.0}

Cómo citar este artículo: Cuadra Lira, E. (2020). Desmovilización sin reinserción: lecciones desde Nicaragua. Papel Politico, 25. https://doi.org/10.11144/Javeriana.papo25.drln. 